\title{
Developing the Next Generation of Leaders in Oral Health
}

\author{
Elsbeth Kalenderian, D.D.S., M.P.H.; Russell S. Taichman, D.M.D., D.M.Sc.; \\ Angelique Skoulas, D.D.S., M.P.A.; Nader Nadershahi, D.D.S., M.B.A., Ed.D.; \\ Kristin Z. Victoroff, D.D.S., Ph.D.
}

\begin{abstract}
Given the challenges facing oral health providers as practitioners, community leaders, and educators, expanding dental curricula with an introductory course on leadership is timely and necessary. Such a course will sow the seeds of leadership by defining its importance in the dental profession and creating an understanding that the skills associated with leadership need to be developed over a lifetime. This article reports on a conference session in which a group of faculty members and students discussed the need and value of teaching leadership, compared leadership programs from four U.S. dental schools, and proposed an implementation framework for leadership programs at other dental schools. The moderator led discussion of participants' suggestions for course materials and implementation frameworks in small-group sessions. The participants' responses were captured using standardized worksheets. Time, including faculty members' and students', was considered the biggest barrier to implementing a leadership course. A number of opportunities were identified, including the ability for interprofessional collaboration and the opportunity for students to grow and learn. Creating a core course with optional components was considered the most attractive option. In this experience, the participants gained perspective on the challenges and opportunities for developing a leadership curriculum and were provided with a tangible product for further development.
\end{abstract}

Dr. Kalenderian is Chair, Department of Oral Health Policy and Epidemiology, and Chief of Quality, Office of Clinical Affairs, Harvard School of Dental Medicine; Dr. Taichman is Major Ash Collegiate Professor and Director for the Scholars Program in Dental Leadership, Department of Periodontics and Oral Medicine, University of Michigan School of Dentistry; Dr. Skoulas is Instructor in Oral Health Policy and Epidemiology and Co-Director, Graduate Leadership Studies Program, Harvard School of Dental Medicine; Dr. Nadershahi is Executive Associate Dean and Associate Dean for Academic Affairs, University of the Pacific Arthur A. Dugoni School of Dentistry; and Dr. Victoroff is Associate Dean for Education, School of Dental Medicine, Case Western Reserve University. Direct correspondence and requests for reprints to Dr. Kristin Z. Victoroff, School of Dental Medicine, Case Western Reserve University, 2124 Cornell Road, Cleveland, OH 44016-4905; 216-368-6616; kaz3@case.edu.

Keywords: leadership, leadership training, dental faculty, dental students

Submitted for publication 7/29/12; accepted 12/23/12

A 11 oral health professionals, and dentists in particular, are faced with an ongoing and evolving challenge in both the scope and definition of dental practice. The current challenges reflect changes in our understanding of what health and well-being mean. Equally important are questions about how oral diseases impact our patients from systemic, financial, and psychosocial standpoints. Moreover, patients have become more sophisticated in their understanding of what oral health means to them and their families. With greater frequency, patients are prepared to play advocacy roles on their own behalf to achieve optimal oral health. ${ }^{1,2}$ At the same time, resource limits place an increasing demand on the health care workforce and are reducing the autonomy of the profession. ${ }^{3,4}$ Whether these changes ultimately lead to improvements in how we, as a society, deliver oral health care or erosions in the profession's ability to address the needs of our patients will be determined by a coalition of stakeholders including, but not limited to, patients, politicians, insurance corporations, dentists, and non-dentist oral health providers. Moreover, the complexity of the issues faced by the profession suggests a need for a structured change, for if indeed dentists represent those best educated and equipped to guide the oral health of our nation, then dentists must learn to take a greater role in reframing the health care debate. Equally as important, dentists, as health care providers, must begin to find and implement solutions to the complex issues that represent threats to the oral health of our nation. To do so will require a change in the culture of our profession. To change the professional culture, we must begin with the training of our future colleagues: dental students.

A basic definition of leadership training refers to purposeful expansion of an individual's capacity focused on leadership, in which leaders and groups learn how best to work together in productive and meaningful ways. ${ }^{5}$ As such, a focus on leadership development represents an institution's long-term commitment to build leadership capacity among its 
alumni. Importantly, the focus can serve as an opportunity to bring together resources and individuals who have not traditionally participated in oral health education.

The need for student leadership development is beginning to be acknowledged and addressed. Victoroff et al.'s survey of dental students found that the majority perceived leadership skills to be important for dentists, believed that leadership skills can be learned, and would be interested in participating in leadership development if it were offered at their school. ${ }^{6}$ The American Student Dental Association (ASDA) held its first ASDA National Leadership Conference in November 2012, indicating that students nationally are realizing the importance of leadership skills in their professional lives. Programs at the University of Michigan School of Dentistry, Case Western Reserve University School of Dental Medicine, Harvard School of Dental Medicine, and the University of the Pacific Arthur A. Dugoni School of Dentistry have been described in published articles. $^{7-10}$

These programs are uniquely adapted to their particular contexts, but share significant overlap in content and design. Content areas common to all four programs suggest that there is agreement that leadership competencies should encompass improvement of communication skills, ability for self reflection, critical thinking, problem-solving skills, emotional intelligence, negotiation, conflict management, and appreciation of the importance of vision development and strategic planning. Notably, professionalism, ethics, and social responsibility are seen as essential aspects of the ability to set goals for a team and move the team towards those goals.

When one is designing a leadership program for dental professionals, a central tenet that must be accepted is the belief that leadership skills can and must be learned. ${ }^{11}$ With respect to design, there is wide agreement that, for many individuals, leadership development is best accomplished through a process of active adult learning. Simply offering occasional motivational speakers to showcase programs that expose students to issues or requiring service without learning and instruction in practice management do not represent fully developed leadership training activities. Moreover, leadership development should not focus exclusively on the acquisition of management skills; for leadership is focused on vision, and management is focused on implementation.

All four programs thus focus on expanding the individual's ability to lead (including developing self-awareness about one's own strengths, values, and improvement areas) and adoption of a broad perspective on issues facing the profession as a whole. The importance of relationships is a core value shared by these programs, and each places an emphasis on individuals working together and networking in the professional context. The need for role models and mentors is also recognized. Finally, the value of involving students in program design and implementation is acknowledged. The purpose of this article is to address the need to develop the next generation of leaders in oral health, beginning with students, and to report the outcomes of a symposium at the 2012 American Dental Education Association (ADEA) Annual Session \& Exhibition on the value of teaching leadership.

\section{Methods}

During the 2012 ADEA Annual Session \& Exhibition, a ninety-minute seminar was presented titled "Engaging the Next Generation of Leaders in Oral Health: Innovative Models for Student Leadership Development." The session was targeted towards mid-career educators, and seventeen dental educators and dental students participated. The learning focus of this session had been designated as "Teaching, Learning, and Curriculum Development." The learning objectives are shown in Table 1 . Three of

\section{Table 1. Learning objectives for the ninety-minute seminar}

Learning Objectives

1. The participants will discuss the value and need for leadership education in dentistry.

2. The participants will discuss a comparison of four different leadership curricula.

3. The participants will discuss an implementation framework for adding leadership teaching into the curriculum.

4. The participants will explore in breakout groups the ideal experience with regards to course development and implementation steps.

5. The participants will be able to take back a leadership course model for further development and implementation to their institutions. 
the authors (EK, KZV, and RST) provided short presentations, covering background material about the program at each's school (Table 2), and the fourth author (NN) served as moderator. Institutional Review Board approval was granted at all the authors' institutions, and informed consent was granted both orally and in written form at the start of the discussion and data collection period.

After the presentations and a short question and answer period, the participants were asked to complete a questionnaire consisting of three questions: 1) what barriers do you perceive to the creation of a leadership development program in the dental/ dental hygiene curriculum? 2) what opportunities do you perceive that could facilitate the creation of a leadership development program in the dental/ dental hygiene curriculum? and 3) what would the ideal leadership development program look like? After that, the participants were asked to organize themselves into small groups and discuss the three questions among themselves. After fifteen minutes of discussion, the groups reported out on each question, and the moderator facilitated a vigorous discussion among the participants.

\section{Results}

As the moderator facilitated the discussions and reports from the participants, the three presenters transcribed the groups' reports and tabulated data from the individually completed questionnaires. The answers on the questionnaires and the transcribed results from the moderated discussion were similar (Table 3).

Time was consistently considered the primary barrier with respect to the creation of a leadership course in dental curricula. The participants explained that this related to student, as well as faculty, availability. The overriding concern was the time that faculty members would need to dedicate for close one-on-one mentoring if the program were to reach the goal of being transformational. However, this could be achieved if participation was tied to tangible outcomes, like scholarship. Funding was the next most frequently mentioned barrier to implementing a leadership course; participants cited the cost of faculty, guest lecturers, and, to a lesser extent, materials as significant expenses that would need to be covered in creative ways by endowments, grants, alumni contributions, and/or school contributions. Considerable concern was expressed regarding the current strained financial climate of most dental schools, resulting in reluctance to start new and major initiatives. Institutional support was a third barrier cited, with support from the dean as the leading barrier. The participants agreed that support from the top was absolutely necessary for success, with support from other administrators and faculty members also important. Other faculty members were considered relevant for their experience as leaders and for their ability to recruit suitable guest lecturers. Program interest by the students was seen as a potential barrier, with selection bias a potential issue if the course was voluntary and if only those students who already consider themselves leaders enroll. Finally, ideological differences around the definition of leadership were mentioned as a potential, but likely resolvable, barrier.

The participants were optimistic about the opportunities a leadership course would create. They noted the value of collaboration across departments, faculties, schools within a university, and indeed professions. Also, the participants were enthusiastic about the opportunity to take on new challenges and assume an empowered role as the profession tries to meet challenges ahead. The potential to develop communication skills among students and other professionals was considered a significant benefit. Finally, the participants said a leadership course as part of a dental curriculum would increase awareness of the importance of leadership in the profession and could, as a side benefit, help to attract strong applicants to schools that offer such a course.

The group agreed that the ideal course would be a combination of a mandatory core program and an elective extended program thereafter. The course would contain practical information easily translatable to the profession, but also into other disciplines. The group expressed the importance that a course be student-driven, with opportunities for individualization, in an effort to allow students to visualize what kind of leader they want to become. The group also acknowledged that a program should take advantage of student contacts and experience, which can be considerable. The course would need to have clear objectives and be well integrated into curricula, with extra/cocurricular as well as curricular opportunities and well-developed opportunities for mentoring by faculty, alumni, and/or upperclass students. Finally, the group suggested that it would be important to longitudinally track the students in an effort to develop a feedback loop to understand how to improve the course over time. 
Table 2. Four dental schools' programs in dental student leadership training

\begin{tabular}{lcc} 
Institution & Program Began & Program Name \\
\hline $\begin{array}{l}\text { University of Michigan } \\
\text { School of Dentistry }\end{array}$ & 2006 & $\begin{array}{l}\text { Scholars Program in Dental } \\
\text { Leadership (UM-SPDL) }\end{array}$
\end{tabular}

Case Western Reserve University School of Dental Medicine

$$
2008
$$

Student Leadership

Development Program

Harvard School of Dental Medicine

University of the Pacific Arthur A. Dugoni School of Dentistry
2009

Concepts of Oral Health Leadership

2010 Dugoni Practical Leadership Initiative (DPLI)
Description

- "To empower dental and dental hygiene students to envision and promote cultural changes in the realm of dentistry. ... UM-SPDL students are those willing to wrestle with global issues facing the dental profession."

- Optional/extracurricular

- Dental and dental hygiene students (all years)

- Selection process

- Program initiated by faculty, with increasing student responsibility

- Stresses active learning through group projects selected by students and involvement of faculty as project mentors

- Invited speakers series

- Focus on knowledge, skills, and inspiration to lead in a variety of settings

- "Leadership is not the private reserve of a few charismatic men and women. It is a process ordinary people use when they are bringing forth the best from themselves and others. When the leader in everyone is liberated, extraordinary things can happen.."1

- Optional/extracurricular

- Open to all dental students, years 1-4

- Kick-off retreat (half-day), plus eight monthly events (20 hrs total)

- Faculty-student collaboration

- Active learning in the classroom setting; panel discussions with role models; personal vision and goals for development

- Two perspectives:

- Individual as leader

- Bird's eye perspective (systems analysis and strategic thinking)

- To enhance the ability of graduates to face the "significant challenges every clinician and researcher will face within his or her practice with colleagues, staff, and patients."

- Required course for third-year dental students

- Ten modules (half practice management, half leadership), 54 hours in total

- Designed by faculty; student input through course evaluations

- Active learning in the classroom setting (case studies, exercises), lecture, and discussion with content experts

- "To help students develop practical leadership skills they can apply immediately and in their future endeavors."

- Yourself as leader, yourself as team leader, yourself as community leader

- Optional/extracurricular

- Dental students (years 1-3)

- Four components: six monthly core group meetings, DPLI Speakers Series, mentorship program, practicum

- Faculty-student collaboration initiated by students

1. Kouzes JM, Posner BZ. The leadership challenge. 4th ed. San Francisco: John Wiley, 2007. 


\section{Table 3. Summary of participants' responses to questionnaire}

1. What barriers do you perceive to the creation of a leadership development program in the dental/dental hygiene curriculum?
a. Time
b. Funding
c. Institutional support
d. Program interest
e. Ideological differences

2. What opportunities do you perceive that could facilitate the creation of a leadership development program in the dental/ dental hygiene curriculum?
a. Opportunities for collaboration
b. Professional preparation/development
c. Promotion of student-driven program
d. Increased awareness of importance of leadership in dental profession
e. Ability to attract strong candidates to the dental school

3. What would the ideal leadership development program look like?
a. Small core courses
b. Practical information
c. Student-driven programming
d. Clear objectives
e. Longitudinal programming

\section{Discussion}

This small, qualitative study was developed as an initial effort to obtain input from other faculty members and students in how leadership training might be further framed, given the fact that four schools have already implemented successful programs. It is clear that several design considerations should be well thought out in advance of developing a leadership program. Essential components of design are the following: 1) whether the program should be embedded or should wrap around the curriculum; 2) if it should be faculty- or student-driven; 3 ) whether students should be brought into the program early or later in their professional development; and 4) whether the program should have a single cohort (e.g., D1, D2, D3, or D4 students) or multiple cohorts (e.g., D1 through D4 students). Many models are available to develop curricular content, including the use of cases, simulations and projects/practicum, and guest speakers with specific expertise. Although we briefly summarize here the major details of the leadership courses in the authors' institutions, it is outside the scope of this article to address those and other leadership courses in detail. Our intent is to start the dialogue around the need for additional research and discussion for leadership education in the dental curriculum.
The participants in this seminar supported the concept that leadership is a valuable content area for a dental student preparing to enter the professional practice of oral health care. The qualitative outcomes of the survey help refine a promising framework that dental schools may used to introduce student leadership development programs by capitalizing on opportunities and finding innovative solutions to real and perceived barriers.

The time and funding barriers consistently and urgently mentioned by the participants will require current leaders in academic dental institutions to make tough decisions if they are committed to participating in the needed culture change of our profession and, as such, support the training of dental students in leadership skills. As Heifetz et al. explained, ${ }^{12}$ tough decisions are challenging for deans for a number of reasons: only one of two equally strong and important curriculum initiatives can be implemented because of time, financial, or other restraints; deans must choose between the current reality of a curriculum that is working well although it could be better and an unknown change in the curriculum that might create a disruption; implementing a leadership curriculum might mean forgoing other projects that might entail loss to those involved or a true loss if new faculty members get hired and former faculty members are reassigned because previous courses have been eliminated; as national resources for scholarship 
dwindle, faculty members may perceive engaging in leadership studies as a distraction from activities directly linked with scholarship and promotion (e.g., research and grants); and personal values might be in conflict if deans prefer to use consensus decision making but the faculty is deadlocked over implementing a leadership curriculum.

It should also be noted that time constraints have always been barriers for curricular innovation, yet identifying opportunities for student engagement is often dictated by local parameters of each academic institution. However, it is important to consider that engaging a change in and of itself can build momentum, in which case even small steps towards change can result in significant outcomes. Leadership success breeds individuals who want to participate once the word gets out. In fact, creating opportunities in even a tight schedule may lead to significant self-selection of students, which may lead to greater returns on the time investment as students who self-select into leadership studies are often the most motivated individuals, who are ready to expand their dental experiences. It is this group that will carry such an initiative forward through peer-to-peer influence and connections.

Both faculty members and students perceive dental student leadership development to be important, and such programs can energize students to be leaders who will solve the challenges faced by dentistry and the community. ${ }^{10}$ Graduates from a professional doctoral degree program are viewed as leaders in their community and are held to higher standards because of their rigorous training, education, and achievements.

As dental educators, we strive to develop the necessary knowledge, skills, and attitudes to graduate a competent practitioner who is able to meet the oral health care needs of the community and society. Traditionally, this has included a focus on details required to become a competent dental surgeon. Fortunately, this training helps our graduates develop the narrowly focused frame of reference to excel at microsurgical procedures necessary to treat existing disease. Unfortunately, this training may also prevent a student from continuing to nurture the dispositions and wide-angle frame necessary for effective leadership and broader understanding of issues in the profession and community. ${ }^{12}$

In order to capitalize on the opportunities outlined in this study of collaboration and holistic professional growth of students to better prepare them for the evolution of interprofessional practice and the politics of health care, leadership development must be at least considered part of the curricular or cocurricular experience of a dental student. Our responsibility is to allow students to develop the narrow focus necessary for success in practice with a balance of big picture thinking and leadership skills necessary to face the challenges of the future in our profession and communities.

A potential challenge in accepting leadership development as a priority for our graduates lies in what we as dental educators value. Shifting our own perspective from one in which the most value is placed on the focus on detail to one that includes a more expanded perspective challenges our traditional approach. As such, our own self-awareness becomes important in accepting a change in perspective and influencing others. ${ }^{13}$ Thinking of the shift in mindset that is required from a both/and perspective could be useful in understanding the goal. By including leadership in our curricula, our graduates would have both the technical expertise necessary for a clinician/ researcher and the expanded and curious view of an effective leader.

A newly developed leadership program should blend seamlessly with other programs with a small core foundational curriculum supported by active involvement in practical application of that foundation. However, the majority of the curricular content should, and is, best taught to individuals who are receptive hosts, rather than as part of a mandate. Another suggested key to success is that the program be student-driven and that participants are surveyed into the future to assess the impact and strengthen the learning experience. Moreover, the development of a leadership program with true student partners cannot help but take advantage of the talent gift and experiences represented by the students. To develop such a program, the findings of this qualitative study suggest that the individual or groups championing this idea will need a clearly defined idea of the support and need for such a program, as well as a clear definition of its goals and objectives. The next step of obtaining broad-based support from the top of the organization, along with the necessary resources, both financial and human, will likely be easier to obtain.

\section{Conclusion}

This article reports on a conference session in which dental students and faculty members discussed the need and value of teaching leadership. Analysis 
of qualitative data from the participants indicated that perceived barriers to development of leadership programs include time, funding, institutional support, student interest, and ideological differences in how leadership is defined. The participants perceived that the development of a leadership program would provide such opportunities as increased collaboration within and outside the dental school, increased awareness of the importance of leadership in the profession, enhanced professional development of students, and, as a secondary benefit, the ability to attract strong candidates for admission to schools with such programs. The participants gained perspective on the challenges and opportunities for developing a leadership curriculum and provided tangible suggestions for the implementation of a framework for leadership programs at other dental schools. For any leadership curriculum to be successful, a clear definition of its goals and objectives, as well as obtaining broad-based support, will be essential.

The challenges facing oral health providers as practitioners, community leaders, and educators are significant. These include substantial changes in the national health care environment; access to care issues; the need to implement and adapt to rapidly changing technology; the challenge of meeting the oral health care needs of a growing, medically complex geriatric population; increased national emphasis on interprofessional collaborative practice; the rising cost of dental education; a national faculty shortage; ethical, professional, and regulatory issues; and the need to disseminate new scientific information, adjust practice patterns to incorporate that information, and interpret that information for individual patients and the public. ${ }^{14-18}$ Each of these challenges represents an opportunity to demonstrate leadership and effect positive change. If the profession is to fulfill its mission to advance the oral health of the public, then such leadership will be needed, now and in the future.

\section{REFERENCES}

1. Douglass CW, Sheets CG. Patients' expectations for oral health care in the 21st century. J Am Dent Assoc 2000;131(Suppl):3S-7S.
2. Willeford R. Discretionary dentistry. In: Economics D, ed. The dentistry IQ network. Tulsa, OK: Dentistry iQ, 2000.

3. Pindus NM, Greiner A. The effects of health care industry changes on health care workers and quality of patient care: summary of literature and research. Washington, DC: Urban Institute, 1997.

4. International Council of Nurses, International Hospital Federation, International Pharmaceutical Federation, et al. Guidelines: incentives for health professionals. Geneva: Global Health Workforce Alliance, World Health Organization, 2008.

5. McCauley CD, Moxley RS, Velsor EV, eds. The handbook for leadership development. San Francisco: Jossey-Bass, 1998.

6. Victoroff KZ, Schneider K, Perry C. Leadership development for dental students: what do students think? J Dent Educ 2008;72(9):982-8.

7. Taichman RS, Green TG, Polverini PJ. Creation of a scholars program in dental leadership (SPDL) for dental and dental hygiene students. J Dent Educ 2009;73(10):113943.

8. Victoroff KZ, Schneider K, Perry C. Tomorrow's leaders, starting today: a pilot leadership development program for dental students. J Dent Educ 2009;73(3):311-8.

9. Kalenderian E, Skoulas A, Timothe P, Friedland B. Integrating leadership into a practice management curriculum for dental students. J Dent Educ 2010;74(5):464-71.

10. Hammer DA, Nadershahi NA. Assessing the demand and preferred format of a student leadership development program at Pacific. J Dent Educ 2011;75(8):1044-52.

11. Skoulas A, Kalenderian E. Leadership training for postdoctoral dental students. J Dent Educ 2012;76(9):1156-66.

12. Heifetz RA, Grashow A, Linsky M. The practice of adaptive leadership: tools and tactics for changing your organization and the world. Boston: Harvard Business Press, 2009.

13. Heifetz RA. Leadership without easy answers. Cambridge: Harvard University Press, 1994.

14. Schmitt M, Andrieu SC, Blue A, et al. Core competencies for interprofessional collaborative practice. Paper presented at Team-Based Competencies Conference, 2011, Washington, DC.

15. Wilder RS, O’Donnell JA, Barry JM, Galli DM, Hakim FF, Holyfield LJ, Robbins MR. Is dentistry at risk? A case for interprofessional education. J Dent Educ 2008;72(11):1231-7.

16. Slavkin HC, Lawrence L. Incorporating leadership knowledge and skills into the dental education community. J Dent Educ 2007;71(6):708-12.

17. Goldstein AO, Calleson D, Bearman R, et al. Teaching advanced leadership skills in community service (ALSCS) to medical students. Acad Med 2009;84(6):754-64.

18. Nash DA. On ethics in the profession of dentistry and dental education. Eur J Dent Educ 2007;11(2):64-74. 